\title{
Tick tock. Tick tock. Tic-tic-tic-tic: If you watch the pot long enough, it boils
}

\author{
James R. Edgerton, MD, FACS, FACC, FHRS
}

\footnotetext{
From the Department of Cardiac Surgery, Heart Hospital Baylor Plano, Plano Tex; and The Texas Quality Initiative, Irving, Tex.

Disclosures: Dr Edgerton is a paid consultant for AtriCure

Received for publication Jan 20, 2017; accepted for publication Jan 28, 2017; available ahead of print March 2, 2017.

Address for reprints: James R. Edgerton, MD, FACS, FACC, FHRS, P.O. Box 190667, Dallas, TX 75219 (E-mail: James.Edgerton@BSWHealth.org).

J Thorac Cardiovasc Surg 2017;153:1095-6

0022-5223/\$36.00

Copyright (c) 2017 by The American Association for Thoracic Surgery

http://dx.doi.org/10.1016/j.jtcvs.2017.01.032
}

In this issue of the Journal, Damiano and colleagues ${ }^{1}$ provide 5-year results of surgical ablation (SA) concomitant to coronary artery bypass grafting (CABG). Given the problems associated with following referral patients over 5 years, this is a laudable effort. In surgical and catheter ablation literature filled with glowing 1-year results, this type of long-term follow-up, reported according to the 2012 Consensus Statement, ${ }^{2}$ is sorely needed. And the results are sobering: $70 \%$ of patients were free of atrial tachyarrhythmias and off antiarrhythmic drugs at 5 years. These results are similar to a previously reported larger group of 512 patients who had a 66\% similar outcome. ${ }^{3}$ These papers, in the modern reporting era of continuous rhythm monitoring, contrast with their 2003 report of $98 \%$ freedom from $\mathrm{AF}$ at 5 years in patients undergoing CABG/maze. ${ }^{4}$ This real, honest follow-up tells us:

- the longer we look, the more we see;

- atrial fibrillation (AF) should be considered a progressive disease; and

- we need to use the word "cure" with great caution.

Despite these things, we need to be aggressively treating our operative patients who have AF. AF is present in $6 \%$ of patients undergoing $\mathrm{CABG},{ }^{5}$ yet only $33 \%$ of these patients receive SA. ${ }^{6}$ In a 2010 third-party survey, among reasons surgeons listed for not doing a maze procedure were as follows: results are not reproducible, adds too much risk, and no consensus on what works. Despite these being shown to be untrue, ${ }^{7}$ the percent of CABG patients with $\mathrm{AF}$ receiving $\mathrm{SA}$ increased only from $27.5 \%$ between 2005 and 2010 to $33 \%$ between 2011 and 2015 . $^{7}$ Certainly some of the undertreatment stems from a reluctance to open the atrium in an otherwise "closed atrium" procedure: whereas more than $68 \%$ of mitral patients with AF undergo concomitant SA, those numbers are $39.3 \%$ for aortic valve replacement $\pm \mathrm{CABG}$ and $33 \%$ for isolated $\mathrm{CABG}{ }^{6}$ Clearly, despite the fact that there is now a Class 1

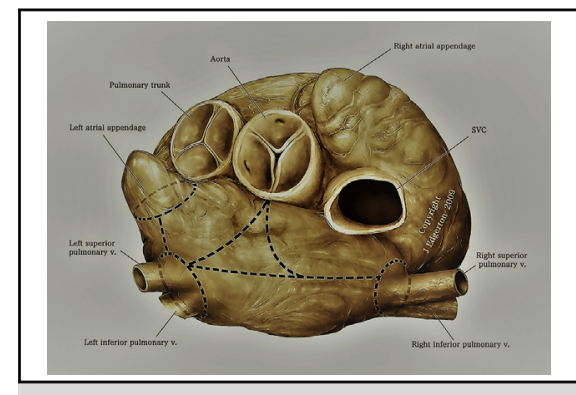

The Dallas lesion set connects to the anterior mitral annulus at the central fibrous body.

\section{Central Message}

Despite there being a Class I recommendation to perform a concomitant ablation of atrial fibrillation, currently only $33 \%$ of patients with atrial fibrillation undergoing coronary artery bypass grafting receive surgical ablation.

See Article page 1087.

(strong, benefit $>>>$ risk) recommendation $^{8}$ to perform concomitant SA in these "closed atrium" patient groups, there is a treatment gap.

How can we begin to bridge this gap? Most of the lesions of the maze IV procedure can be approached epicardially (on the empty atrium) with cryothermy or directional bipolar radiofrequency, or through purse strings using constrained bipolar (clamp) radiofrequency. It is the mitral annular connecting lesion that enjoins one to open the left atrium. Acknowledging that the maze IV is the desired treatment strategy, perhaps an alternate approach to the mitral connecting lesion would increase the adoption of concomitant ablation. Two such approaches exist. The Dallas lesion set $^{9,10}$ connects to the anterior mitral annulus at the left fibrous trigone. The epicardial landmark for this is the junction of the left and noncoronary cusps of the aortic valve in the transverse sinus (Figure 1). Taking inspiration from the Dallas lesion set, Weimar and colleagues ${ }^{11}$ have described performing this same lesion endocardially, through the opened aorta-most useful when performing SA concomitant to for aortic valve replacement.

When faced with evidence for the efficacy of new therapies such as the use of the internal mammary and mitral valve repair, surgeons have adopted new treatment paradigms. Will we rise to the challenge to perform concomitant SA? 


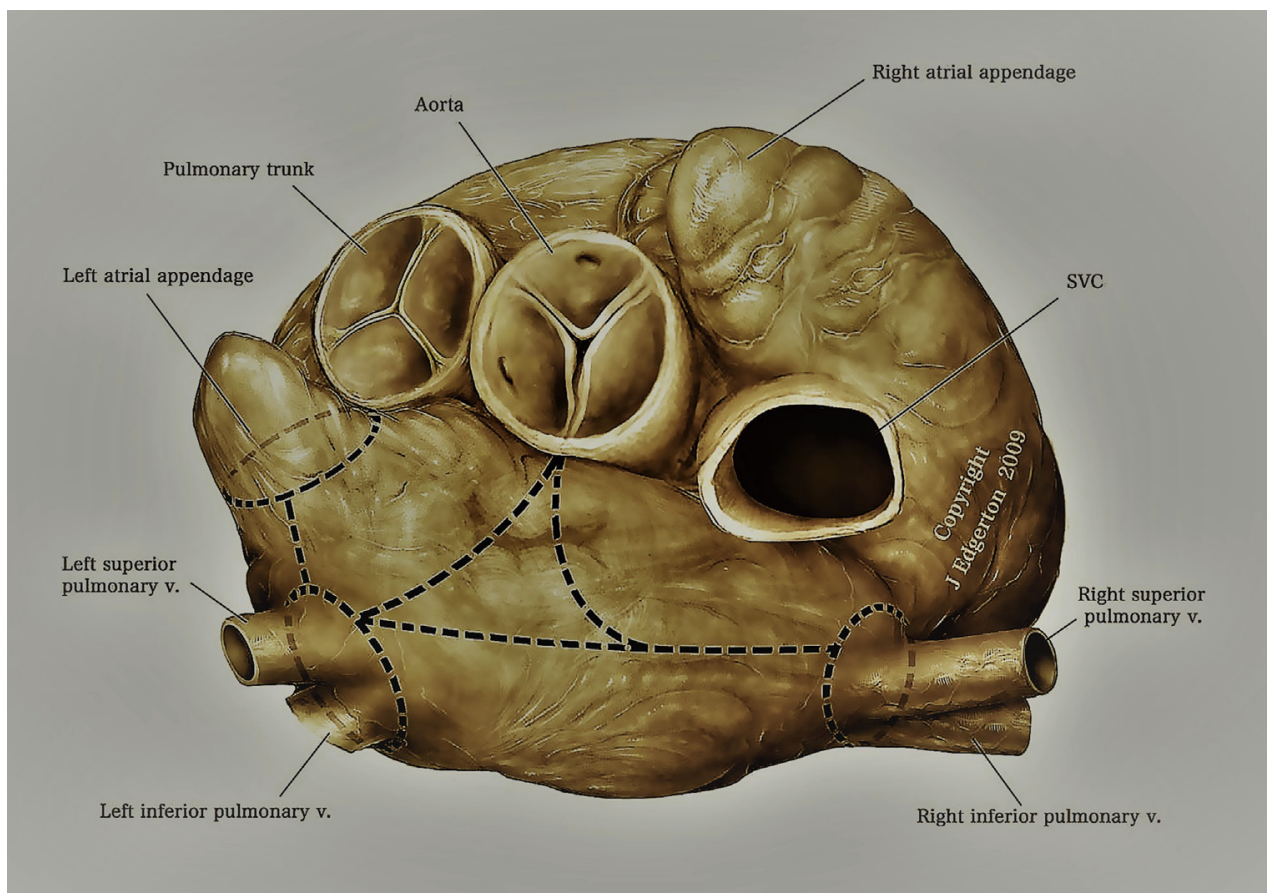

FIGURE 1. The Dallas lesion set connects to the anterior mitral annulus at the central fibrous body. $S V C$, Superior vena cava; $v$, vein.

\section{References}

1. Schill MR, Musharbash FN, Hansalia V, Greenberg JW, Melby SJ, Maniar HS, et al. Late results of the Cox-maze IV procedure in patients undergoing coronary artery bypass grafting. J Thorac Cardiovasc Surg. 2017;153:1087-94.

2. Calkins H, Kuck KH, Cappato R, Brugada J, Camm AJ, Chen SA, et al; Heart Rhythm Society Task Force on Catheter and Surgical Ablation of Atrial Fibrillation. 2012 HRS/EHRA/ECAS expert consensus statement on catheter and surgical ablation of atrial fibrillation: recommendations for patient selection, procedural techniques, patient management and follow-up, definitions, endpoints, and research trial design: a report of the Heart Rhythm Society (HRS) Task Force on Catheter and Surgical Ablation of Atrial Fibrillation. Developed in partnership with the European Heart Rhythm Association (EHRA), a registered branch of the European Society of Cardiology (ESC) and the European Cardiac Arrhythmia Society (ECAS); and in collaboration with the American College of Cardiology (ACC), American Heart Association (AHA), the Asia Pacific Heart Rhythm Society (APHRS), and the Society of Thoracic Surgeons (STS). Endorsed by the governing bodies of the American College of Cardiology Foundation, the American Heart Association, the European Cardiac Arrhythmia Society, the European Heart Rhythm Association, the Society of Thoracic Surgeons, the Asia Pacific Heart Rhythm Society, and the Heart Rhythm Society. Heart Rhythm. 2012;9:632-96.

3. Henn MC, Lancaster TS, Miller JR, Sinn LA, Schuessler RB, Moon MR, et al Late outcomes after the Cox maze IV procedure for atrial fibrillation. $J$ Thorac Cardiovasc Surg. 2015;150:1168-76. 78.e1-2.

4. Damiano RJ, Gaynor SL, Bailey M, Prasad S, Cox JL, Boineau JP, et al. The long-term outcome of patients with coronary artery disease and atrial fibrillation undergoing the Cox maze procedure. J Thorac Cardiovasc Surg. 2003;126: 2016-21.

5. Gammie JS, Hadad M, Milford-Beland S, Welke KF, Ferguson TB Jr, O'Brien SM, et al. Atrial fibrillation correction surgery: lessons from the Society of Thoracic Surgeons National Cardiac Database. Ann Thoracic Surg. 2008;85: 909-14.

6. Badhwar V, Rankin S, Ad N, Grau-Sepulveda M, Damiano RJ, Gillinov AM, et al. Surgical ablation of atrial fibrillation in the United States: contemporary trends and propensity matched outcomes. Presented at: 63rd Annual Meeting of The Southern Thoracic Surgical Association; November 9-12, 2016; Naples, FL.

7. Ad N, Suri RM, Gammie JS, Sheng S, O'Brien SM, Henry L. Surgical ablation of atrial fibrillation trends and outcomes in North America. J Thorac Cardiovasc Surg. 2012;144:1051-60.

8. Badhwar V, Rankin JS, Damiano RJ, Gillinov AM, Bakaeen FG, Edgerton JR, et al. The Society of Thoracic Surgeons 2017 clinical practice guidelines for the surgical treatment of atrial fibrillation. Ann Thoracic Surg. 2017;103: $329-41$.

9. Edgerton JR, Jackman WM, Mack MJ. A new epicardial lesion set for minimal access left atrial Maze: the Dallas lesion set. Ann Thorac Surg. 2009; $88: 1655-7$.

10. Edgerton JR. Total thorascopic ablation of atrial fibrillation using the Dallas lesion set. Partial autonomic denervation, and left atrial appendectomy. Op Tech Thorac Cardiovasc Surg. 2009;14:224-42.

11. Weimar T, Gaynor SL, Seubert DY, Damiano RJ, Doll N. Performing left atrial maze ablation pattern without atriotomy. Ann Thorac Surg. 2016;101:777-9. 